\title{
GOCE: precise orbit determination for the entire mission
}

\author{
Heike Bock • Adrian Jäggi · Gerhard Beutler • \\ Ulrich Meyer
}

Received: 18 February 2014 / Accepted: 7 June 2014 / Published online: 2 July 2014

(C) Springer-Verlag Berlin Heidelberg 2014

\begin{abstract}
The Gravity field and steady-state Ocean Circulation Explorer (GOCE) was the first Earth explorer core mission of the European Space Agency. It was launched on March 17, 2009 into a Sun-synchronous dusk-dawn orbit and re-entered into the Earth's atmosphere on November 11, 2013. The satellite altitude was between 255 and $225 \mathrm{~km}$ for the measurement phases. The European GOCE Gravity consortium is responsible for the Level $1 \mathrm{~b}$ to Level 2 data processing in the frame of the GOCE High-level processing facility (HPF). The Precise Science Orbit (PSO) is one Level 2 product, which was produced under the responsibility of the Astronomical Institute of the University of Bern within the HPF. This PSO product has been continuously delivered during the entire mission. Regular checks guaranteed a high consistency and quality of the orbits. A correlation between solar activity, GPS data availability and quality of the orbits was found. The accuracy of the kinematic orbit primarily suffers from this. Improvements in modeling the range corrections at the retro-reflector array for the SLR measurements were made and implemented in the independent SLR validation for the GOCE PSO products. The satellite laser ranging (SLR) validation finally states an orbit accuracy of $2.42 \mathrm{~cm}$ for the kinematic and $1.84 \mathrm{~cm}$ for the reduced-dynamic orbits over the entire mission. The common-mode accelerations from the GOCE gradiometer were not used for the official PSO product, but in addition to the operational HPF work a study was performed to investigate to which extent common-mode accelerations improve the reduced-dynamic orbit determination results. The accelerometer data may be used to derive realistic constraints for the empirical accelerations estimated for the reduced-dynamic orbit determination, which already
\end{abstract}

H. Bock ( $\varangle)$ · A. Jäggi · G. Beutler · U. Meyer

Astronomical Institute of the University of Bern, Sidlerstrasse 5, 3012 Bern, Switzerland

e-mail: heike.bock@aiub.unibe.ch improves the orbit quality. On top of that the accelerometer data may further improve the orbit quality if realistic constraints and state-of-the-art background models such as gravity field and ocean tide models are used for the reduceddynamic orbit determination.

Keywords GOCE - Precise orbit determination - GPS . Accelerometer $\cdot$ SLR $\cdot$ Solar activity

\section{Introduction}

The Gravity field and steady-state Ocean Circulation Explorer (Floberghagen et al. 2011, GOCE) was the first Earth explorer core mission of the Living Planet Programme of the European Space Agency (ESA). The satellite was launched on March 17, 2009 from Plesetsk, Russia into a Sun-synchronous duskdawn orbit with an inclination of $96.6^{\circ}$. The initial altitude was $280 \mathrm{~km}$, which was then lowered to $254.9 \mathrm{~km}$ (mean semi-major axis minus the Earth radius at the equator) during the first months of the mission. This exceptionally low altitude was maintained by the drag-free and attitude control system (DFACS), which compensated the non-gravitational forces acting in nominal flight direction by an ion propulsion assembly (Andreis and Canuto 2005). Since August 2012, the orbital altitude of the satellite was lowered stepwise by $30 \mathrm{~km}$ to about $224 \mathrm{~km}$. In the first hours of October 21, 2013 , the ion thruster ran out of fuel and the satellite could no longer be held on the measurement altitude. The official end of the mission was declared and after 3 weeks of decay, the GOCE satellite re-entered the Earth's atmosphere in the first minutes of November 11, $2013 .{ }^{1}$

\footnotetext{
$\overline{1}$ http://www.esa.int/For_Media/Press_Releases/GOCE_gives_in_to_ gravity.
} 
The satellite was equipped with a three-axis gradiometer, a main and a redundant satellite-to-satellite tracking instrument (SSTI), and three star cameras. The differential-mode accelerations of the gradiometer are used for extracting rotational accelerations and for the determination of the gravity field (Bouman et al. 2013; Rummel et al. 2011). The common-mode accelerations were used for the realization of the drag-free flight in along-track direction and they may also be used for separating gravitational from non-gravitational forces. Except for some days early in 2011, the main SSTI was running in nominal operation and the GPS (Global Positioning System) tracking data were used for precise orbit determination (POD) of the satellite (Bock et al. 2011b). The star camera data were needed for attitude determination and for deriving the gravity gradients.

As part of the European GOCE Gravity Consortium (EGG-C), the Astronomical Institute of the University of Bern (AIUB) was responsible for the generation of the official Precise Science Orbit (PSO) product within the GOCE Highlevel Processing Facility (Koop et al. 2006, HPF). AIUB has proven the ability for LEO POD in, e.g., for CHAMP (Reigber et al. 2002, CHAllenging Minisatellite Payload,), GRACE (Tapley et al. 2004, Gravity Recovery And Climate Experiment) and MetOp-A (Loiselet et al. 2000) in Jäggi (2007); Jäggi et al. (2007, 2009, 2012); Montenbruck et al. (2008). Specific adaptations of the available GRACE POD procedure for GOCE were shown in Bock et al. (2007) and Visser et al. (2009). GOCE POD results for the first 2 months of the measurement phase from November and December 2009 were presented by Bock et al. (2011b).

LEO POD on the level of few $\mathrm{cm}$ is, in general, only possible if antenna phase center offsets and variations (PCVs) are consequently taken into account, because they are an important systematic error source in POD (Jäggi et al. 2009). The PCVs for the main SSTI antenna of GOCE were, therefore, generated by an in-flight calibration based on 154 days of data (Bock et al. 2011a). Operational orbit determination was continuously performed from April 2009 until the official end of the mission in the early morning of October 21, 2013, when the Xenon gas tank got empty and the drag-free flight could no longer be maintained. The results presented in the first part of this article (Sect. 2) cover the entire mission period including the commissioning phase from April 7, 2009 to October 20, 2013.

The operational PSO processing for the reduced-dynamic orbit did not make use of the common-mode accelerometer data. In addition to the HPF activities a study was, therefore, performed to assess the potential of these data for reduceddynamic orbit determination. The usage of accelerometer data in orbit determination had already been studied for other satellites carrying an accelerometer, e.g., for CHAMP and GRACE. Since accelerometer data are biased, the estimation of calibration parameters in the orbit determination process is an important aspect. van Helleputte et al. (2009) and van Helleputte (2011) estimated these calibration parameters successfully for CHAMP and GRACE using GPS data. Kang et al. (2006) used GRACE accelerometer data for orbit determination and estimated the calibration parameters as well. The estimation of the scale factors for a short time period of GOCE was, however, only reliable during non-drag-free periods, because of the reduced signal in along-track during drag-free periods (van Helleputte 2011).

Section 2 presents results from the official PSO determination for the HPF and model improvements for the external validation with satellite laser ranging (SLR) measurements. The study including accelerometer data in the reduced-dynamic orbit determination is discussed in Sect. 3. Section 4 summarizes the findings of this article.

\section{Official orbit determination: Precise Science Orbit (PSO)}

The PSO consists of a reduced-dynamic (Jäggi et al. 2006) and a kinematic (Švehla and Rothacher 2005) orbit. They are generated in one processing chain with an arc length of $30 \mathrm{~h}$. The orbits are computed with a tailored HPF version of the Bernese GPS Software (Dach et al. 2007) using an approach based on zero-difference GPS data processing. The GOCE PSO generation is described in detail in Bock et al. (2007, 2011b). The dynamical and measurement models used are summarized in Table 1.

The PSO is available since April 7, 2009 and was continuously delivered as long as SSTI data were available. The availability of the SSTI data may be checked from the official ESA website. ${ }^{2}$ The monthly Level 1B (L1B) data reports ${ }^{3}$ contain information on the quality of the data. The physical models (European 2010) and the orbit parametrization used for processing were the same for the entire mission. This holds in particular for the empirical parametrization of the reduced-dynamic orbit, where three constant accelerations over the entire orbital arc of $30 \mathrm{~h}$ were set up and 6-min piece-wise constant accelerations in radial, along-track, and out-of-plane were estimated with the same constraints for the entire mission. The SSTI antenna and laser retro-reflector offsets, however, changed due to fuel consumption and the resulting movement of the center-of-mass of the satellite. The center-of-mass coordinates were published and updated on a regular basis by ESA. ${ }^{4}$

The generation of the PSO was based on an automated procedure, which ran on a daily basis. Before submitting the product to the other HPF groups and to ESA, manual quality

\footnotetext{
$\overline{2 \text { http://earth.eo.esa.int/missions/goce/SSTI/. }}$

${ }^{3}$ http://earth.eo.esa.int/missions/goce/monthly/.

${ }^{4}$ https://earth.esa.int/web/guest/-/goce-mass-property-file- 8276.
} 
Table 1 Summary of dynamical and measurement models employed for the orbit determination of GOCE

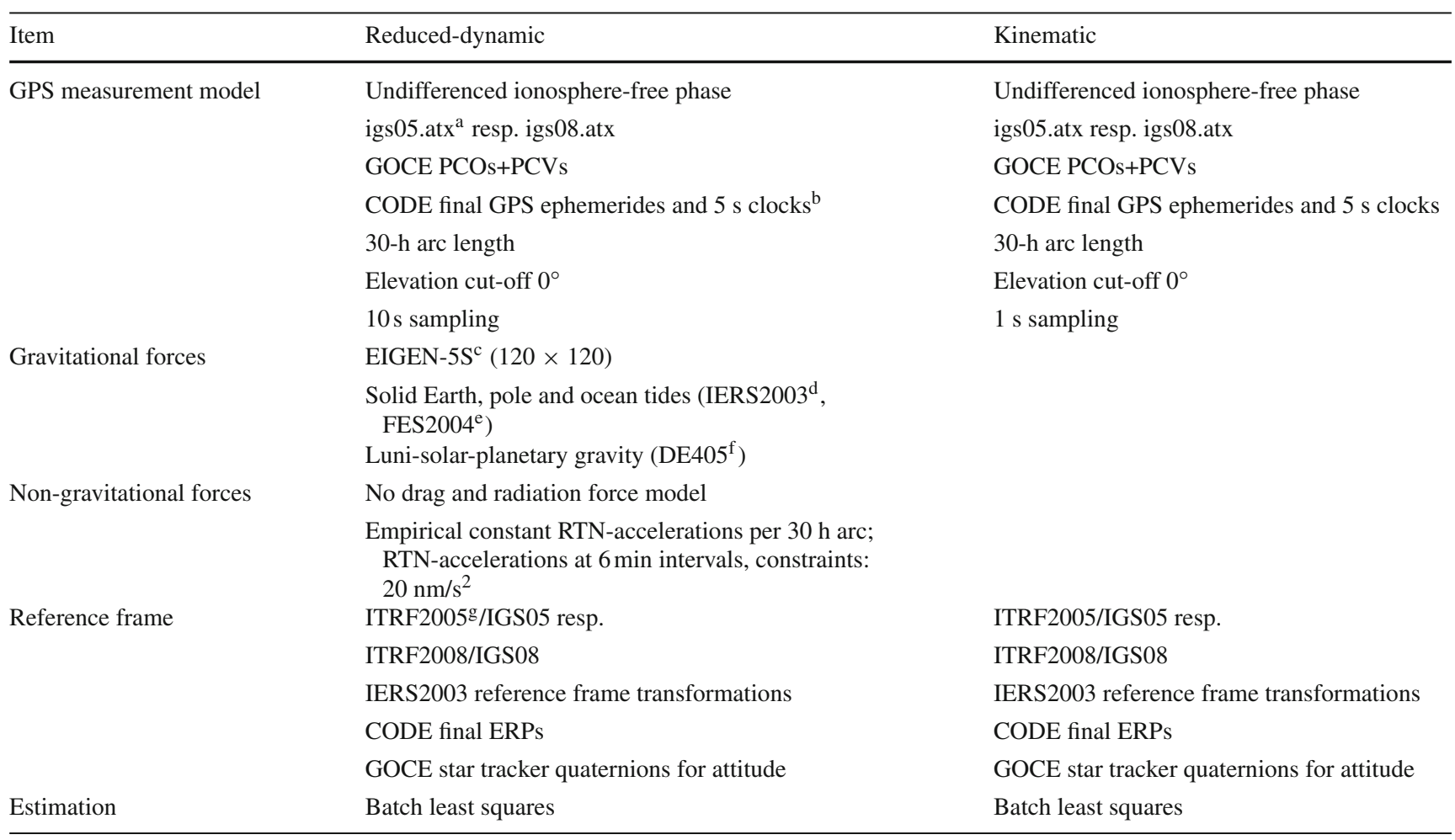

a Schmid et al. (2007), used until April 16, 2011

b Bock et al. (2009)

${ }^{\mathrm{c}}$ Förste et al. (2008)

d McCarthy and Petit (2004)

e Lyard et al. (2006)

${ }^{\mathrm{f}}$ Standish (1998)

g Altamimi et al. (2007),

used until April 16, 2011

checks (orbit overlaps and consistency) were performed to guarantee quality and consistency.

\subsection{Operational processing}

\subsubsection{Orbit overlaps}

The processing batches of $30 \mathrm{~h}$ allow it to study the overlaps between two consecutive arcs. In order to avoid boundary effects only $5 \mathrm{~h}$ overlap periods (21:30-02:30) are checked. Figure 1 shows the RMS values of the overlaps for the reduced-dynamic orbits in radial, along-track, out-of-plane directions, as well as the 3D overlaps for the entire mission until October 20, 2013. The large data gap in summer of 2010 was caused by a problem in the satellite telemetry causing data loss for about 2 months (Floberghagen et al. 2011). Except for very few days, the overlaps are very consistent at a level of $1 \mathrm{~cm}$ in 3D. At the very beginning of the mission in April 2009, the attitude data were incomplete or not available at all and between 12 and 28 February 2010, a spacecraft anomaly occurred (Floberghagen et al. 2011). These are only

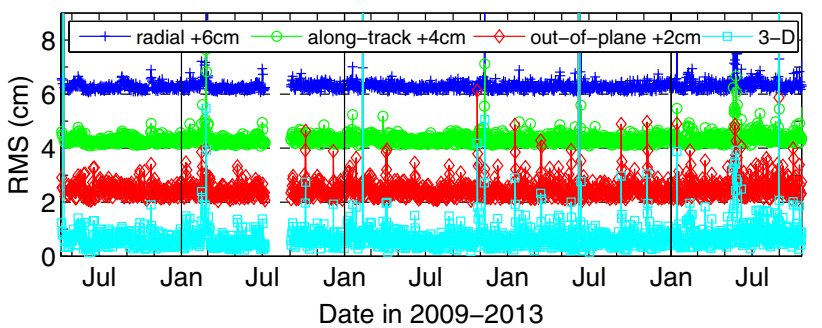

Fig. 1 PSO-RMS of 5-h overlaps of the reduced-dynamic orbits for entire mission; values for radial, along-track and out-of-plane directions are shifted $+6 \mathrm{~cm},+4 \mathrm{~cm}$ and $+2 \mathrm{~cm}$, respectively

two examples of special events, for most of the other days where the RMS of the overlaps is exceptionally high a responsible event may be found in the monthly L1B data reports, as well. The parametrization of the reduced-dynamic orbit was not optimized for these days, and the constraints for the accelerations might be too tight. Therefore, the RMS of the overlaps shows larger values than normal on these days. The parametrization was not adapted for these days. Obviously, this is not ideal for all days, but this strategy is easy to realize and it is traceable in an operational environment. 


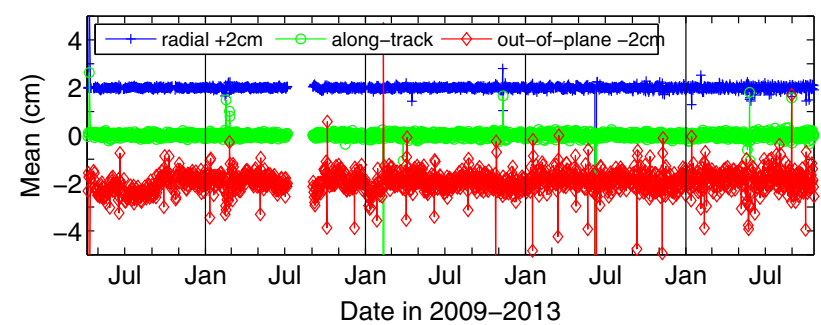

Fig. 2 PSO-mean offsets of 5-h overlaps of the reduced-dynamic orbits for entire mission; mean offsets in radial and out-of-plane direction are shifted $+2 \mathrm{~cm}$ and $-2 \mathrm{~cm}$, respectively
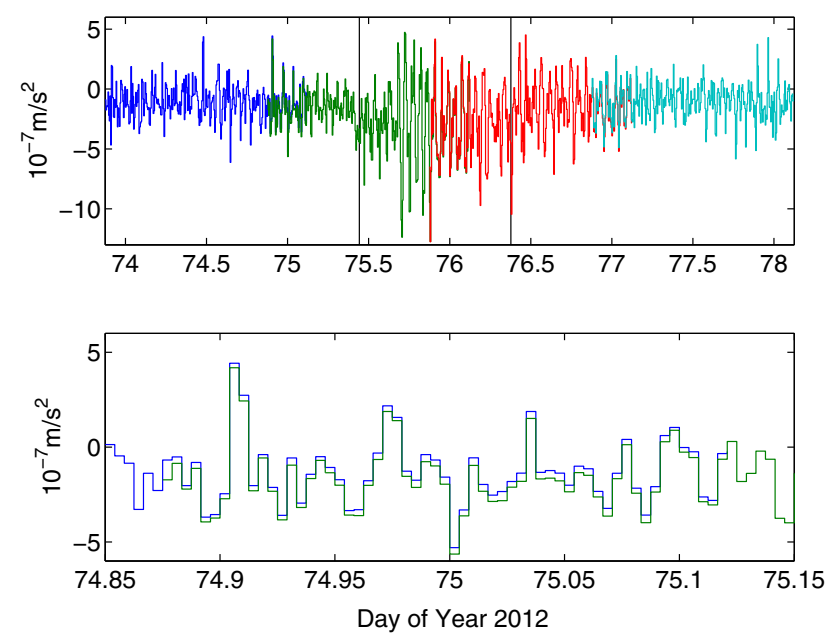

Fig. 3 Top estimated empirical accelerations in out-of-plane direction for days 074-077 (14-17 March) in 2012; bottom zoom into overlap interval from day 074 and 075 (14 and 15 March), 2012

Inspecting the corresponding mean values of the overlaps in Fig. 2, one can notice that in general the out-of-plane component shows larger variations and has a larger noise than the two other components. This is because the out-of-plane component is very sensitive to systematic errors in POD (Jäggi et al. 2009).

In addition, one may notice that often the mean values of the out-of-plane direction are significantly larger and of opposite sign for consecutive days. This happened on days when the gradiometer calibration took place..$^{5}$ For this purpose, the satellite was shaken (Frommknecht et al. 2011). The shaking periods lasted for about $24 \mathrm{~h}$, e.g., from 10:37:37 UTC on 15 March 2012 to 09:03:32 UTC on 16 March 2012. As the calibration started in the middle of the day, three consecutive days are affected in the overlap statistics. Figure 3 shows the estimated empirical (6-min piece-wise constant) accelerations plus the estimated constant acceleration in out-of-plane direction for four consecutive days centered around the gradiometer calibration on 15-16 March, 2012 (days 075-076, 2012). The duration of the calibration is marked by the two black vertical lines in the

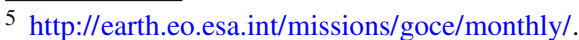

top panel. The estimated accelerations are noticeably larger during the calibration period, due to the additional accelerations caused by the shakings. The bottom figure presents a zoom into the overlap interval from 14 and 15 March, 2012 (days 074 and 075). There is a constant offset between the accelerations of days 074 and 075 of about $3 \times 10^{-8} \frac{m}{s^{2}}$. Using the relationship (Meindl et al. 2013)

$\delta w=\frac{W}{n^{2}}$

with the mean motion $n$ of the satellite and the acceleration $W=3 \times 10^{-8} \frac{\mathrm{m}}{\mathrm{s}^{2}}$ in out-of-plane direction, we obtain an offset $\delta w$ of approx. $2.2 \mathrm{~cm}$. This value corresponds to the mean offset of $-2.24 \mathrm{~cm}$ in the overlaps for the reduced-dynamic orbits of days 074 and 075,2012 and to the equivalent offset with opposite sign of $+2.00 \mathrm{~cm}$ for the accelerations between days 076 and 077, 2012. The constant acceleration difference in the out-of-plane direction leads to a constant offset between the reduced-dynamic orbits of the consecutive days. The constant difference in the out-of-plane accelerations is caused by a too tight constraining for the piece-wise constant accelerations, which does not allow to compensate the much larger accelerations in the out-of-plane direction caused by the satellite shaking.

\subsubsection{Orbit consistency}

The differences between the reduced-dynamic and the kinematic orbits provide another internal quality measure. These differences give no direct information about the orbit accuracy, but they are indicators for data quality, because kinematic orbits are very sensitive to data quality. Figure 4 shows the arc-wise RMS of these differences in the radial, alongtrack, and out-of-plane directions, as well as the 3D values for the entire mission. The differences used for the statistics are computed every $10 \mathrm{~s}$ only, because the reduced-dynamic orbit is sampled to this interval. In order not to deteriorate the daily values by single outliers in the kinematic orbits, differences larger than $1 \mathrm{~m}(<0.5 \%)$ were removed from the statistics.

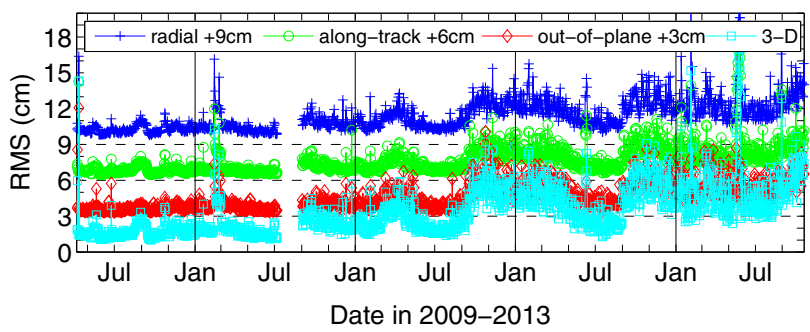

Fig. 4 PSO - comparison between reduced-dynamic and kinematic orbits; RMS of the orbit differences; values for radial, along-track and out-of-plane directions are shifted $+9 \mathrm{~cm},+6 \mathrm{~cm}$ and $+3 \mathrm{~cm}$, respectively 
The RMS of the differences in essence shows the same signature in all components. The days with large values in the overlaps show also larger RMS values in the differences between the reduced-dynamic and kinematic orbits. The RMS of the differences is, however, not at the same level for the entire time interval. Starting with September 2010, the differences got slightly larger and in the periods of March/April 2011, October 2011-April 2012, and from September 2012 until the end of the mission the RMS of the differences is significantly larger in all components. The mean values listed in Table 2 confirm in numbers the increase in the RMS values. Figure 5 shows similar signatures as in the orbit differences for the mean total electron content (TEC), estimated by the Center for Orbit Determination in Europe (Dach et al. 2009, CODE), reflecting the solar activity, as well as for the percentage of missing data on the second GPS frequency (L2) and of missing kinematic positions in the PSO. The correlation between these three quantities and the increased RMS of the differences between reduced-dynamic and kinematic orbits (Fig. 4) are obvious. Even seasonal variations, e.g., the minima around July and maxima around November, are at the same places in all displayed quantities. The correlation between the mean TEC and the 3D RMS values in Fig. 4 is 0.70, between mean TEC and missing L2 data 0.86 and between mean TEC and missing kinematic positions 0.74 .

The impact of missing L2 observations on the GPS data availability was already reported by van den IJssel et al. (2011). Observations are mainly missing in the polar regions

Table 2 Mean RMS (cm) values from differences between reduceddynamic and kinematic orbits

\begin{tabular}{lllll}
\hline Year & Radial & Along-track & Out-of-plane & 3D \\
\hline 2009 & 1.31 & 0.91 & 0.73 & 1.77 \\
2010 & 1.65 & 1.10 & 0.96 & 2.22 \\
2011 & 2.36 & 1.64 & 1.72 & 3.38 \\
2012 & 2.97 & 2.13 & 2.19 & 4.30 \\
2013 & 3.57 & 2.70 & 2.65 & 5.27 \\
$2009-2013$ & 2.41 & 1.73 & 1.69 & 3.45 \\
\hline
\end{tabular}

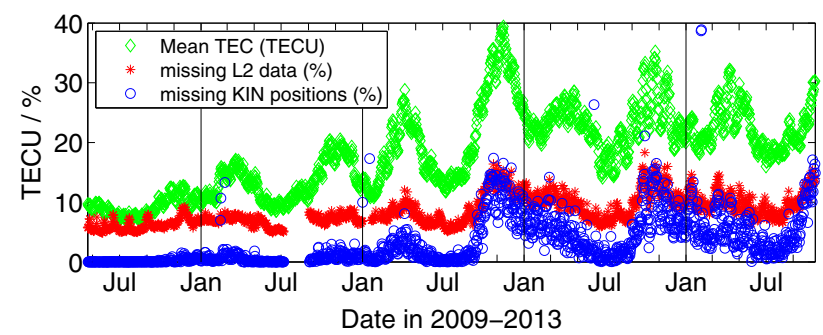

Fig. 5 Mean TEC (TECU) values and corresponding percentage of missing L2 data and missing kinematic positions in the PSO near the geomagnetic poles and around the geomagnetic equator. The increasing solar activity visibly documented by the mean TEC values had obviously a negative influence on the tracking performance of the SSTI-and the situation got worse with the years. Additionally, the ascending node of the GOCE orbit was not fixed, but was slowly moving from initially 18:00 local time towards midnight. By the beginning of April 2013, the local time of the ascending node was, therefore, at about 19:20 (M. Fehringer, ESA, private communication). The ascending arcs of the satellite, therefore, passed more and more through an environment of large ionospheric scintillations shortly after dusk (Basu and Groves 2001). This led to increasing tracking problems around the geomagnetic equator for ascending passes.

Figure 6 shows the radial RMS of the differences between reduced-dynamic and kinematic orbits in a geographical distribution for the years 2009 to 2011 separate for ascending (left column) and descending (right column) passes. The RMS values are largest around the geomagnetic poles (Northern Canada/Greenland and south of Australia) and the affected area gets larger year after year. The values themselves also increase from year to year. This development is the main reason for the increasing RMS values in Fig. 4. Other systematics around the geomagnetic equator are visible in these figures, which do, however, not cause the increasing RMS values. These systematics are not very large, but unfortunately they prominently map into the GPS-only gravity field solutions derived from the kinematic positions (Baur et al. 2014). More investigations on these systematics are provided in Jäggi et al. (2014).

In summary, the internal validation of the GOCE PSO product shows that the orbit determination could be run with the same settings for the entire mission irrespective of whether the satellite was in drag-free mode or not. The orbit parametrization for the reduced-dynamic orbit was not ideal for some short time periods in non-drag-free mode, but it was still possible to derive orbit solutions of good quality for these days as well. The kinematic orbit is not sensitive whether the drag-free mode is on or off, and therefore the quality is not directly affected by the flight mode. It is, however, sensitive to data problems and to data gaps and therefore the quality measure derived from comparing reduced-dynamic and kinematic orbits is sensitive to data problems.

\subsection{Improvements in external validation}

Whether the orbit accuracy is significantly affected by the data problems mentioned in the previous section can only be assessed by independent measurements. The SLR measurements to GOCE may serve as such external validations for the GOCE orbits derived from GPS data. In order to support the SLR tracking of GOCE by the International Laser Ranging Service (Pearlman et al. 2002, ILRS), additional orbit 

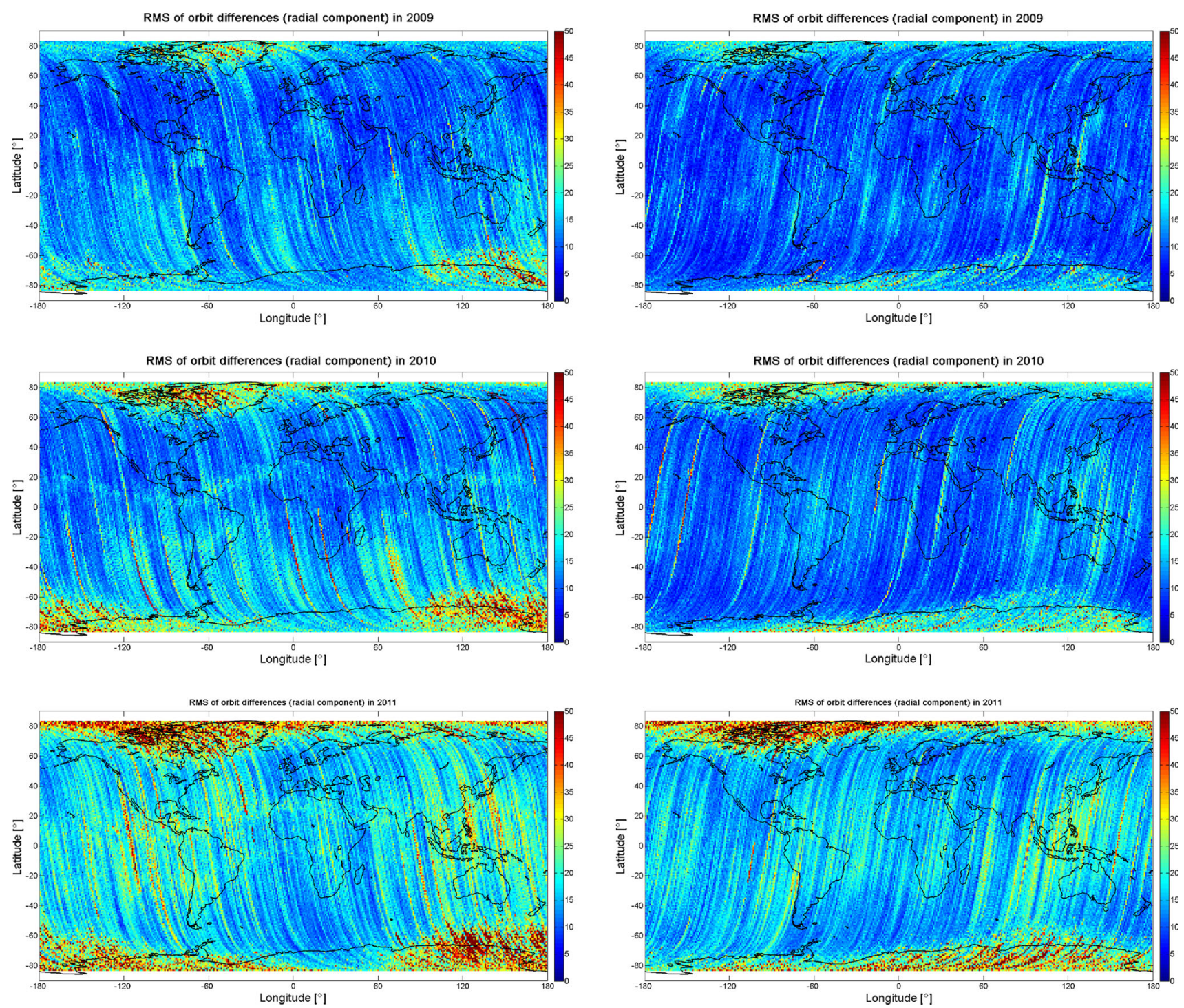

Fig. 6 RMS ( $\mathrm{mm}$ ) of radial differences between reduced-dynamic and kinematic PSO in a geographical distribution separated in ascending and descending passes for 2009, 2010, and 2011

predictions were made available from AIUB based on GPSderived orbits (Jäggi et al. 2011). The models as listed in the GOCE Standards document (European 2010) were used for the validation of the GOCE orbits with SLR measurements.

Nadir-dependent range corrections for the laser retroreflector array on GOCE were made available by ESA (Bigazzi and Frommknecht 2010) at the beginning of the mission. The studies by Bock et al. (2011a,b) used this information for SLR validation. In the meantime, Montenbruck and Neubert (2011) provided several models of azimuthnadir dependent range corrections for the GOCE and CryoSat (SP 2003) laser retro-reflector arrays. The retro-reflector array on GOCE consisted of seven corner cubes. Six cubes were mounted symmetrically around one center cube, and the range correction was then computed depending on the nadir and the azimuth angle of the incoming laser pulse. The corresponding correction map for the nearest-prism approximation [details may be found in Montenbruck and Neubert (2011)], which was selected for the GOCE SLR validation, is shown in Fig. 7.

In addition to the correction map, the tilting angle of $5^{\circ}$ of the retro-reflector array with respect to the satellite body (Bigazzi and Frommknecht 2010) was considered for the validation. In order to check the impact of these two improvements in the external validation of the GOCE orbits, they were applied for the time interval from day 251/2010 to 226/2011 (September 8, 2010-August 14, 2011) in two different test cases parallel to the original settings (nadirdependent + no tilt). The resulting statistics of the validation are contained in Table 3. The standard deviation dropped 
down from 1.82 to $1.45 \mathrm{~cm}$ when applying the tilt of the reflector array. Furthermore, the mean offset got close to zero when additionally applying the range corrections from the improved modeling of the laser retro-reflector array with the nearest-prism approximation. The example shows that small modeling deficiencies in the SLR observable may already be seen in the validation results.

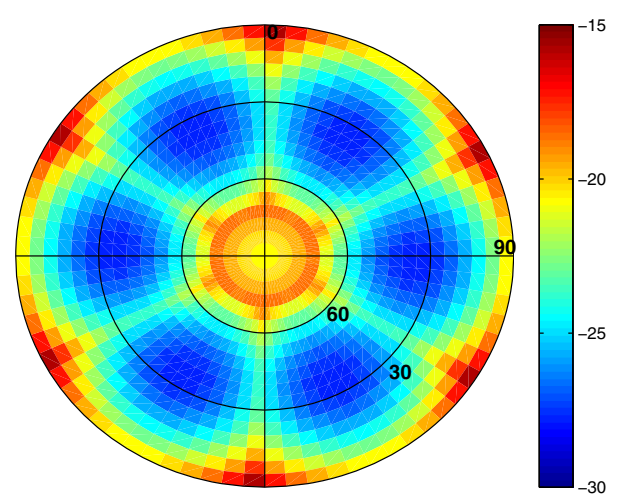

Fig. 7 GOCE azimuth-nadir dependent range corrections $(\mathrm{mm})$ for the laser retro-reflector array (Montenbruck and Neubert 2011, nearestprism approximation,). Azimuth of $0^{\circ}$ nominally points into flight direction

Table 3 SLR validation of reduced-dynamic orbits from day 251/2010-226/2011

\begin{tabular}{lll}
\hline Range corrections + tilt & Mean $(\mathrm{cm})$ & $\begin{array}{l}\text { Standard } \\
\text { deviation }(\mathrm{cm})\end{array}$ \\
\hline Nadir-dependent + no tilt & 0.55 & 1.82 \\
Nadir-dependent $+5^{\circ}$ tilt & 0.52 & 1.45 \\
Nearest-prism & 0.01 & 1.44 \\
approximation $+5^{\circ}$ tilt & & \\
\hline
\end{tabular}

The SLR residuals for the entire mission are shown in Fig. 8 for the reduced-dynamic orbits and in Fig. 9 for the kinematic orbits. The corresponding statistics are listed in Table 4. In order not to deteriorate the validation by single outliers, SLR residuals larger than $20 \mathrm{~cm}(<0.3 \%)$ were excluded. The results for the kinematic orbits are worse than for the reduced-dynamic orbits. This is not surprising, because kinematic orbits are more sensitive to data problems. The yearly values show a degradation of the orbit quality toward the end of the mission. The orbit accuracy suffers from the mentioned data problems and gaps mainly for the kinematic orbits.

The overall RMS value for the reduced-dynamic orbit is $1.84 \mathrm{~cm}$, which is still better than the required $2-\mathrm{cm}$ orbit accuracy. The overall accuracy of the kinematic orbits with $2.42 \mathrm{~cm}$ is slightly larger than $2 \mathrm{~cm}$.

\section{Beyond HPF: orbit determination using accelerometer data}

The six accelerometers on GOCE form the gradiometer. Differential and common-mode accelerations can be derived from their readings. Differential accelerations are used for the gravity field determination. The common-mode accelerations provide a measure of the non-gravitational forces acting on the satellite and they served as input for the DFAC system. The official reduced-dynamic PSO solution did not make use of the common-mode accelerations, because one wanted to be independent from the availability of the common-mode accelerations for the official operational orbit solutions. The question is, however, whether one may get equivalent or even better results by using them in the reduced-dynamic orbit determination process.
Fig. 8 SLR validation for reduced-dynamic orbits of PSO; mean offset $0.18 \mathrm{~cm}$, RMS $1.84 \mathrm{~cm}$

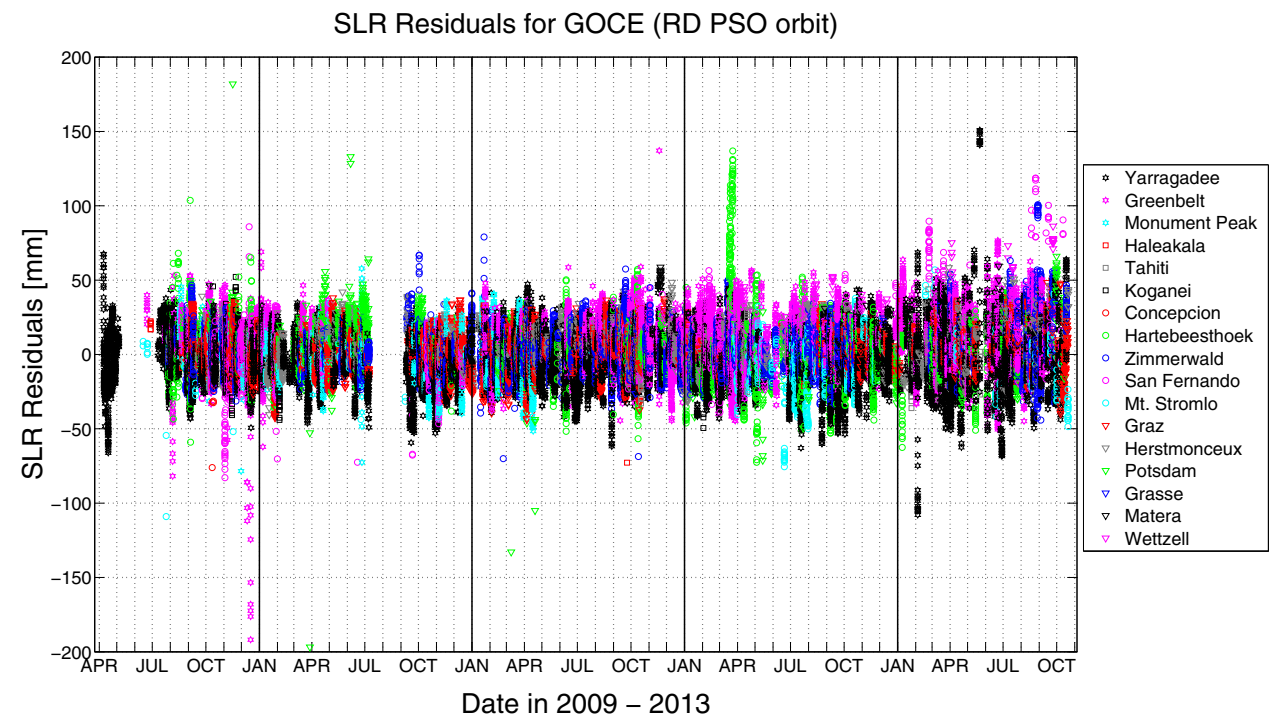


Fig. 9 SLR validation for kinematic orbits of PSO; mean offset $0.10 \mathrm{~cm}$, RMS $2.42 \mathrm{~cm}$

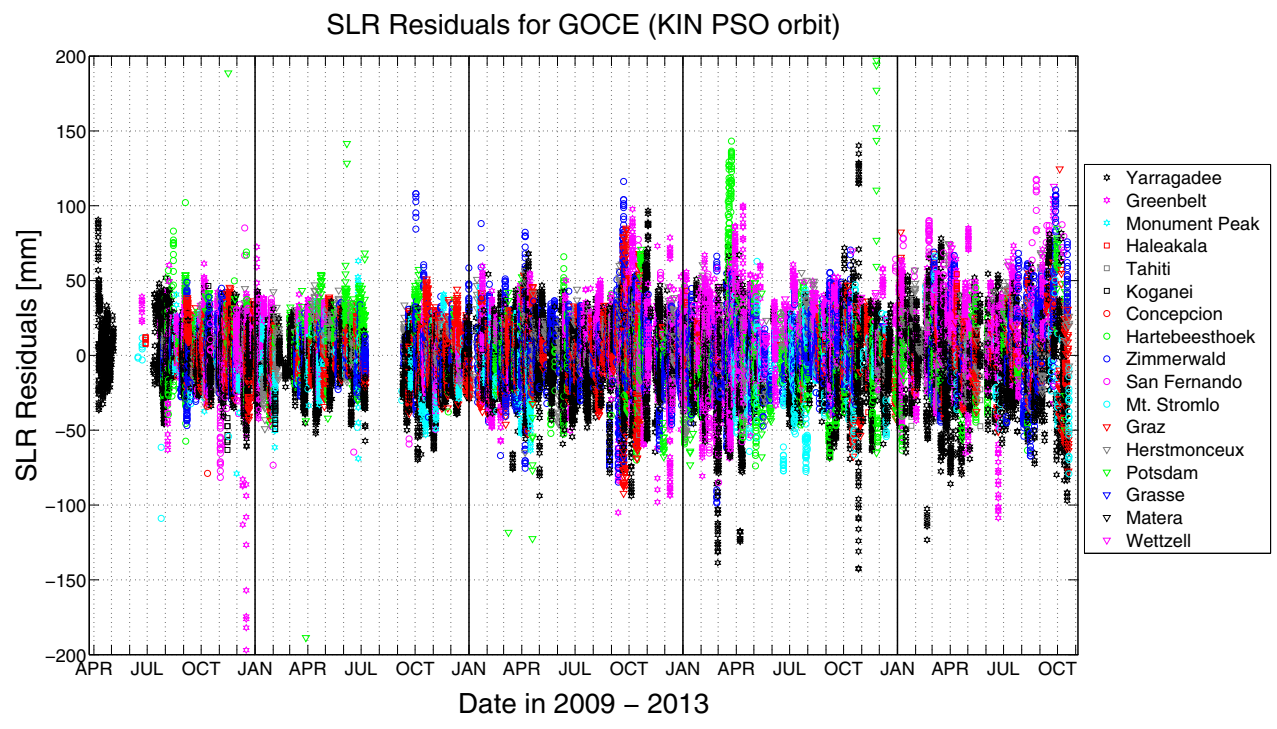

Table 4 SLR validation for both orbit types; mean $(\mathrm{cm}) \pm \mathrm{RMS}(\mathrm{cm})$

\begin{tabular}{lrr}
\hline Year & Red.dynamic & \multicolumn{1}{c}{ Kinematic } \\
\hline 2009 & $0.24 \pm 1.73$ & $0.29 \pm 1.91$ \\
2010 & $-0.10 \pm 1.56$ & $-0.12 \pm 1.84$ \\
2011 & $0.20 \pm 1.53$ & $0.12 \pm 2.36$ \\
2012 & $0.10 \pm 1.94$ & $-0.05 \pm 2.78$ \\
2013 & $0.63 \pm 2.62$ & $0.45 \pm 3.17$ \\
$2009-2013$ & $0.18 \pm 1.84$ & $0.10 \pm 2.42$ \\
\hline
\end{tabular}

\subsection{Characteristics of the accelerometer data}

The GOCE accelerometer data refer to the gradiometer reference frame, which is a right-handed system with $\mathrm{X}$ pointing approximately into flight direction, $\mathrm{Y}$ is orthogonal to $\mathrm{X}$ and is parallel to the instantaneous direction of the orbital angular momentum, and $\mathrm{Z}$ points approximately in nadir direction (European 2010). It would be best to study the accelerometer data in this original XYZ system. For practical reasons, we rotate them into the RAO system, where $R$ points into the radial direction, $\mathrm{A}$ is orthogonal to $R$ within the orbital plane and approximately points into the along-track direction, and $\mathrm{O}$ completes the right-handed system with the outof-plane component. This transformation gives us the possibility to directly compare the accelerometer data with the empirical accelerations estimated in the reduced-dynamic orbit determination for the PSO (which are estimated in the RAO system). Accelerometer data are biased observations. Before rotating the data into the RAO system, a mean offset is subtracted for all three directions, respectively. In the orbit determination process, three constant offsets in the directions of the RAO system are estimated and absorb the remaining offsets in the accelerometer data. Scale parameters are not estimated, because they are very stable and close to one (Bouman et al. 2011).

Figure 10 compares the measured accelerometer data rotated into the RAO-system with the estimated piece-wise constant accelerations from the reduced-dynamic orbit determination for day 306 of the year 2009 (November 2, 2009). In $R$, only a small correlation ( 0.14$)$ between the accelerometer data (red) and the estimated 6-min piece-wise constant accelerations (blue) may be noticed. The comparison in A shows no correlation at all $(-0.01)$. In $\mathrm{O}$, the correlation is pronounced (0.60). The estimated accelerations closely follow the measured accelerometer data.

Our first goal was to find physically more meaningful constraints for the empirical accelerations when not using the accelerometer data for the orbit determination. The official reduced-dynamic PSO is computed with the same constraint for all empirical accelerations in all three directions $\left(\sigma=2.0 \times 10^{-8} \frac{\mathrm{m}}{\mathrm{s}^{2}}, \sigma_{0}=0.001 \mathrm{~m}\right.$ of phase observations). This value was derived empirically at the beginning of the mission. If we look at the different variations in the accelerometer measurements, more realistic values for the constraints may be certainly derived from the accelerometer data themselves (assuming that the neglection of accelerometer data represents the largest source of mismodelings).

Since we used 6-min piece-wise constant empirical accelerations, we took the mean values over $6 \mathrm{~min}$ of the accelerometer measurements and computed the RMS of these mean values over $24 \mathrm{~h}$. We found that the daily RMS values are almost constant over periods of several months (valid for the test period used in Sect.3.2), and therefore one may translate these RMS values to constant constraints for the corresponding directions.

If we use the accelerometer data in the orbit determination process in a further step to model the sum of all nongravitational accelerations, they should replace the empiri- 
Fig. 10 Comparison between accelerometer data and 6-min piece-wise constant accelerations from the reduced-dynamic orbit determination; day 306/2009; top: $R ; 0.14$ correlation coefficient, middle: $\mathrm{A} ;-0.01$, bottom: $O ; 0.60$
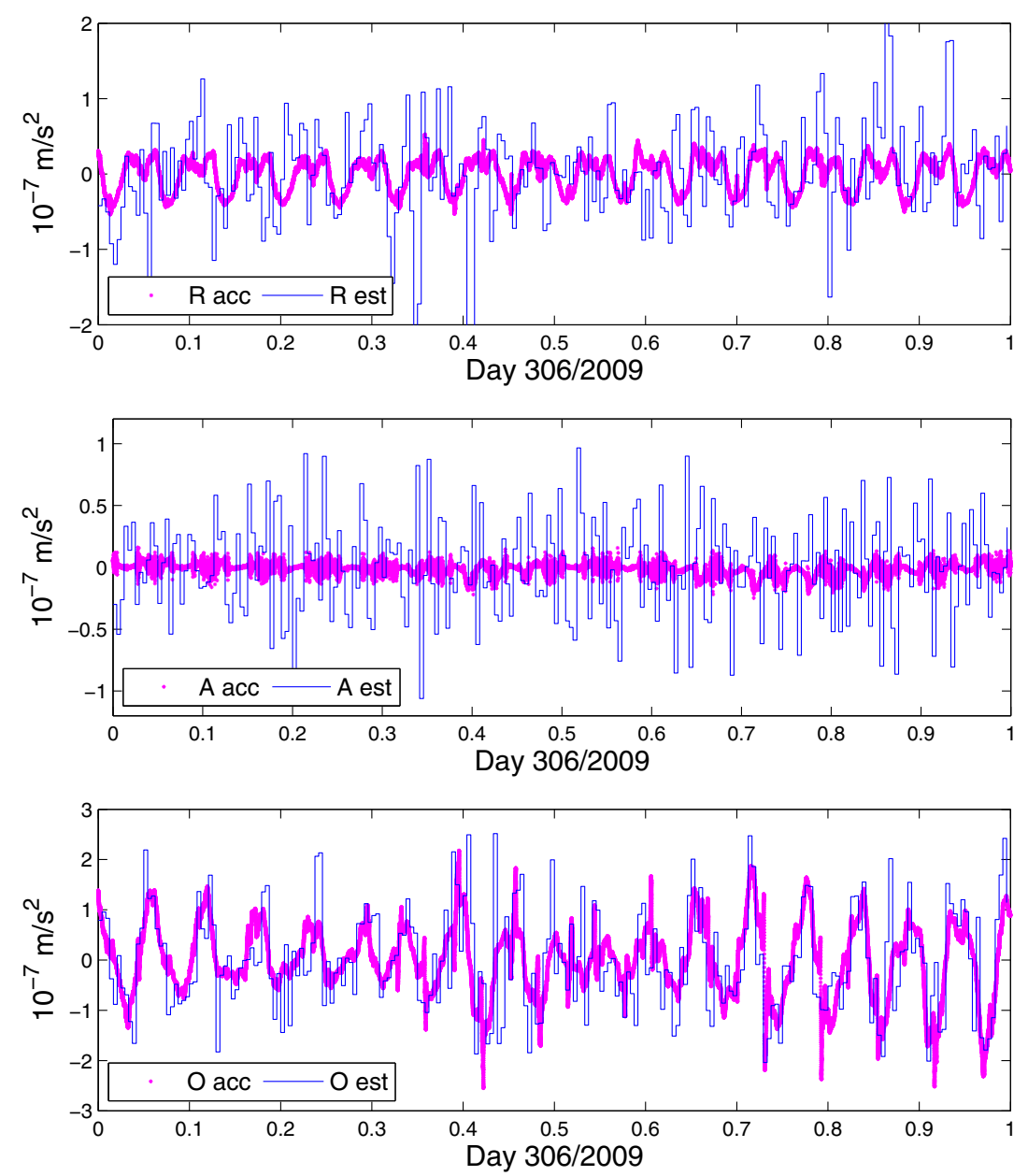

cally estimated accelerations to a large extent. It should thus be possible to tighten the constraints significantly, because only small unmodeled signals should remain to be compensated by the empirical parameters. For this scenario, we use $10 \%$ of the constraint derived from the accelerometer data. This value is empirical in nature.

\subsection{Test scenario}

Different reduced-dynamic orbits with and without using accelerometer data and with different constraints were computed for the time interval from November 2 to December 30, 2009 (306-364/2009). In order to study the impact of the background models, different gravity field and ocean tide models up to different truncation are used as well. As reference solution, we used the official reduced-dynamic PSO solution (central $24 \mathrm{~h}$ ). A detailed description of the models and parameters used may be found in Table 1 .

The models relevant for this study are given in Table 5 . The left column lists the different gravity field and ocean tide models used with different truncations for solution types A, B, C and D. Solution type A is computed without common- mode accelerometer data. Solution types B, C and D are using them in the orbit determination process. The corresponding constraints are listed in the very first row. Solution type 0 uses the same constraint as the official reduceddynamic PSO solution for all three directions. Solution type 1 applies a tighter, but equal constraint for all three directions, and solution type 2 uses different constraints for the three directions, which were derived from the accelerometer data.

Figure 11 shows the estimated accelerations of solution A0 and A2. The only difference between the two solutions is the constraints for the estimated accelerations. The constraints for solution A2 were derived from the measured accelerations and should, therefore, be more realistic than the common constraints used for solution A0. The values listed in the top right of Table 5 were already reduced to $10 \%$ of the values derived from the measured accelerations. For solution A2, these values are thus multiplied again by a factor of 10 , because we do not use the accelerometer data for the orbit determination and the full signal has to be absorbed by the estimated accelerations. In radial direction $R$, where the constraint for solution A2 is still the same as for solution A0, the accelerations are, 
Table 5 Summary of

reduced-dynamic orbit solutions
${ }^{\text {a }}$ Förste et al. (2008)

${ }^{\mathrm{b}}$ Used up to degree and order

${ }^{c}$ Lyard et al. (2006)

${ }^{\mathrm{d}}$ Corresponds to official reduced-dynamic PSO solution

e Constraints are multiplied by factor 10

${ }^{\mathrm{f}}$ Mayer-Gürr et al. (2012)

g Savcenko and Bosch (2008)

Fig. 11 Comparison of estimated accelerations for solution A0 and A2; day 306/2009; top: $R$, middle: A, bottom: $O$

$\sigma=2.0 \times 10^{-8} \frac{\mathrm{m}}{\mathrm{s}^{2}} \quad \sigma=5.0 \times 10^{-9} \frac{\mathrm{m}}{\mathrm{s}^{2}} \quad \begin{aligned} & \sigma_{R}=2.0 \times 10^{-9} \frac{\mathrm{m}}{\mathrm{s}^{2}} \\ & \\ & \\ & \sigma_{A}=4.0 \times 10^{-10^{\frac{m}{s^{2}}}} \\ & \sigma_{O}=7.0 \times 10^{-9} \frac{\mathrm{m}}{\mathrm{s}^{2}}\end{aligned}$

$w / o$ accelerometer data

EIGEN5S ${ }^{\mathrm{a}}\left(120^{\mathrm{b}}\right)$

$\begin{array}{llll}\mathrm{FES}_{2004^{c}}(50) & \mathrm{A} 0^{\mathrm{d}} & \mathrm{A} 1 & \mathrm{~A} 2^{\mathrm{e}}\end{array}$

With accelerometer data

EIGEN5S (120)

$\begin{array}{llll}\text { FES2004 (50) } & \text { B0 } & \text { B1 } & \text { B2 }\end{array}$

GOCO03S $^{\mathrm{f}}(120)$

$\begin{array}{llll}\text { EOT08A }^{\mathrm{g}}(50) & \mathrm{C} 0 & \mathrm{C} 1 & \mathrm{C} 2\end{array}$

GOCO03S (160)

$\begin{array}{llll}\text { EOT08A (50) } & \text { D0 } & \text { D1 } & \text { D2 }\end{array}$
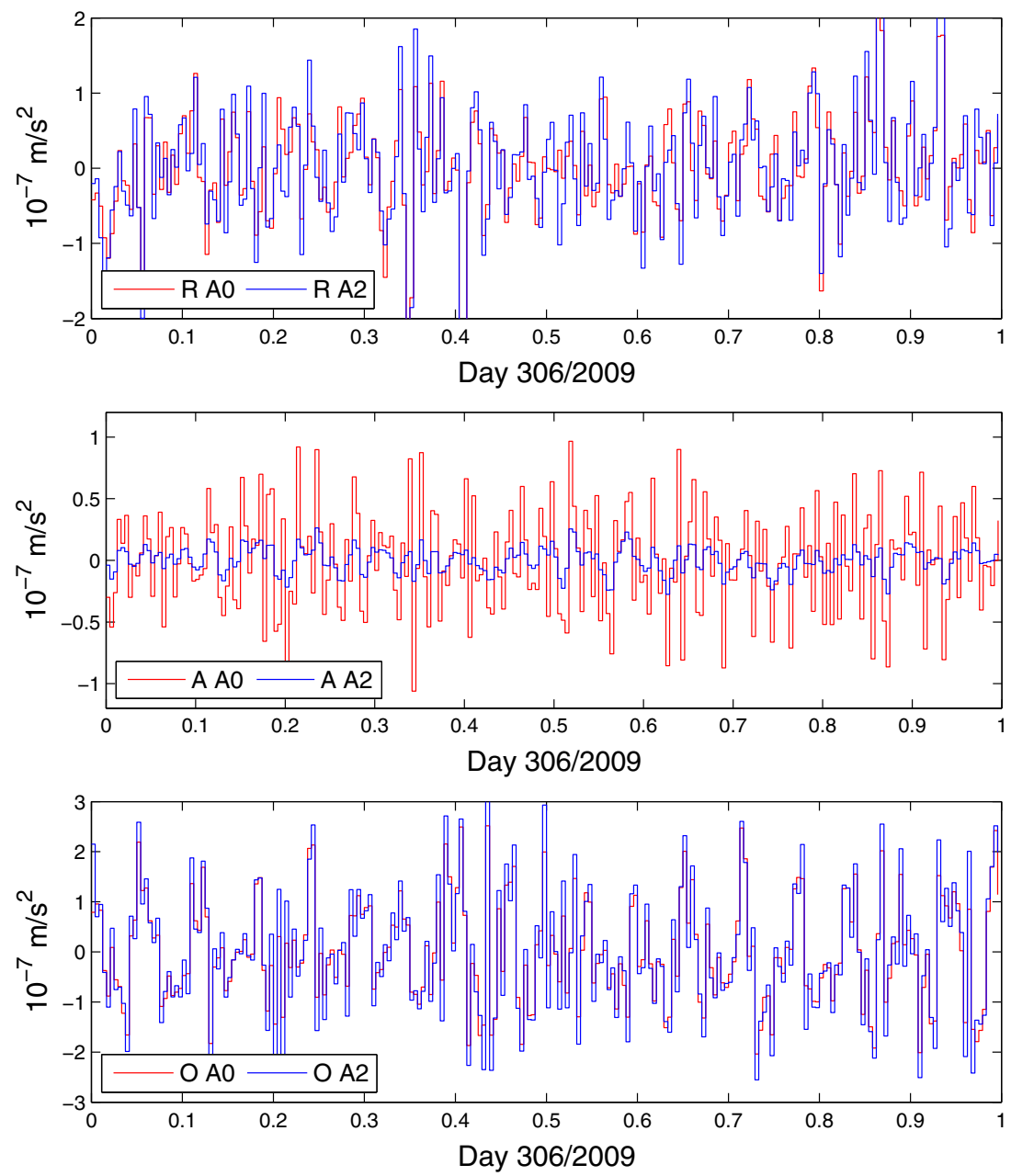

however, slightly different. The correlation to the measured accelerations is 0.24 , and thus larger than for solution A0. The estimated accelerations in along-track direction $\mathrm{A}$ are significantly smaller due to the tighter constraint (correlation to measured accelerations 0.04). Due to the high degree of correlation between the radial and along-track components, the accelerations in $R$ have obviously absorbed some unmodeled signal. The accelerations in out-of-plane direction $\mathrm{O}$ for solution A2 (correlation to measured accelerations 0.51) are slightly larger than for solution A0, which can be explained by the weaker constraint for the $\mathrm{O}$ component for $\mathrm{A} 2$ than for $\mathrm{A} 0$. 
Fig. 12 Comparison of estimated accelerations for solution $\mathrm{A} 0$ and $\mathrm{D} 2$; day 306/2009; top: $R$, middle: A, bottom: $O$
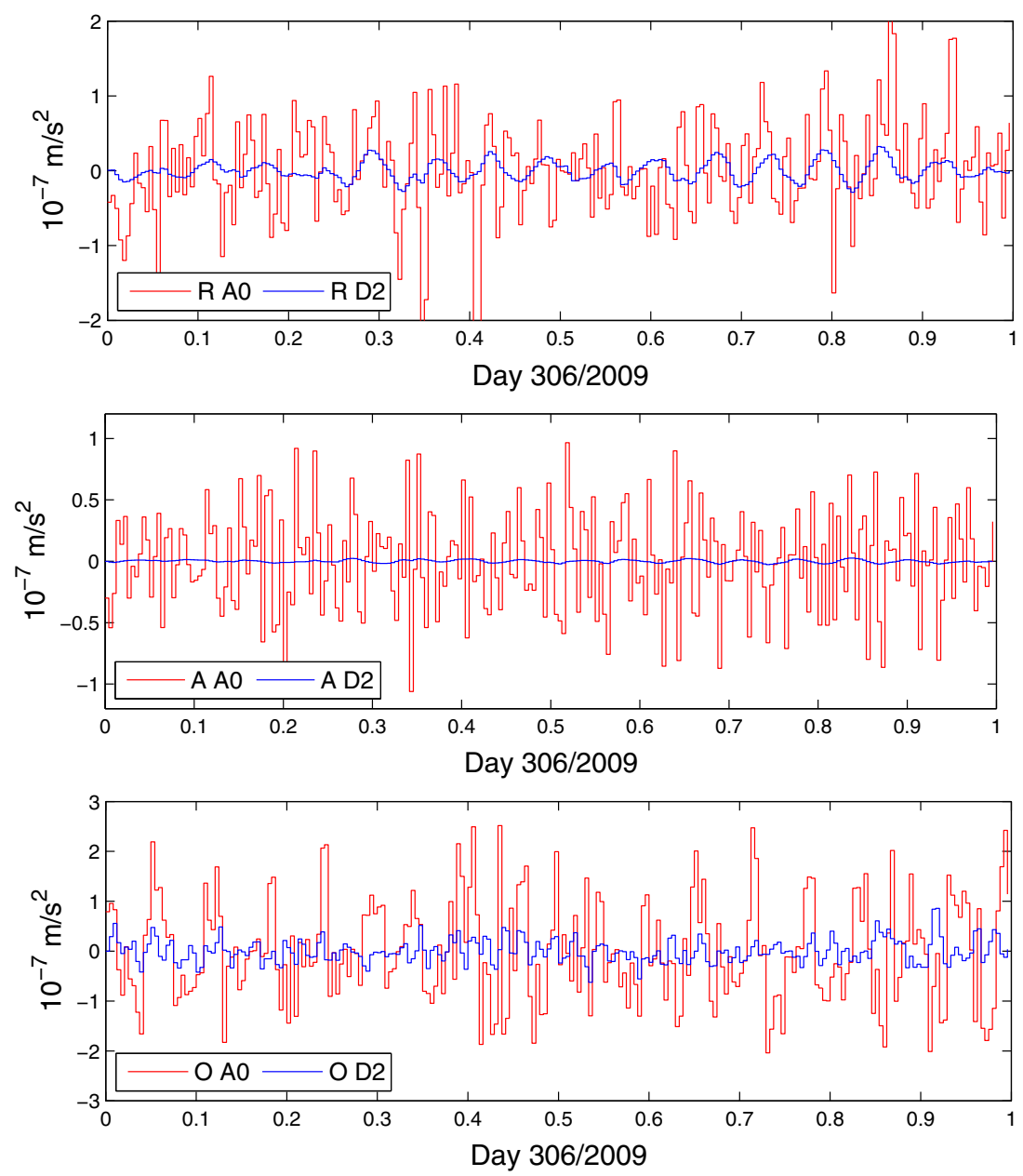

Figure 12 shows the estimated accelerations of solution D2 in comparison to A0. The accelerations are significantly smaller in all three components, which is expected in view of the improved modeling (better gravity field and ocean tide model, higher truncation) and the much tighter constraints for $\mathrm{D} 2$ compared to $\mathrm{A} 0$. The question is whether these small constraints of solution D2 are large enough to compensate for remaining model deficiencies.

The comparisons between the estimated accelerations are, however, not helpful to resolve this question. The quality of the resulting orbits has to be assessed in a different way. Therefore, we inspect the 3D orbit difference between subsequent orbital arcs at midnight. The test solutions are only computed in 24-h batches not allowing for long overlaps. A small orbit difference at midnight means that the subsequent orbits are consistent. The orbit difference at midnight is, therefore, a quality indicator for the solution type. Figure 13 shows these orbit differences for the solution types 0 using the constraints of the reduced-dynamic reference solution. All four solutions A0-D0 are on the same level and no significant differences may be recognized. This might be surprising at first sight, because solutions $\mathrm{B} 0$

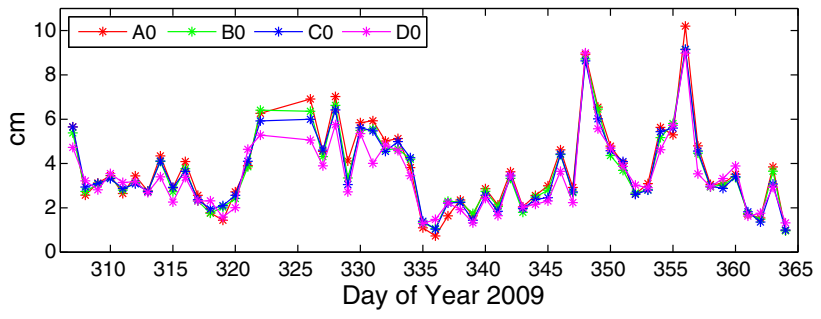

Fig. 13 Orbit differences at midnight for solution types 0

D0 are using the measured accelerometer data in the orbit determination process. In these cases, the constraints are not tight enough and the degree of freedom is too high to benefit from the accelerometer data in the orbit determination process.

Figure 14 shows the orbit differences for solution types A1-D1 together with reference solution A0. The tighter constraints for all components result in a different signature for the orbit differences. Solution A1 is in general worse and Solution D1 in general better than solution A0, but for the other two solutions B1 and $\mathrm{C} 1$ the result is not that clear. 


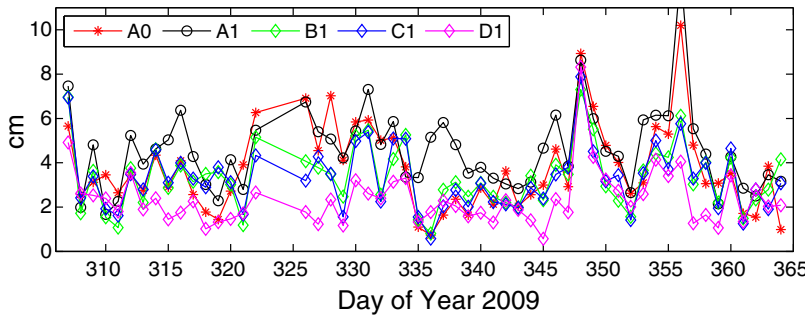

Fig. 14 Orbit differences at midnight for solution types A1-D1 and A0

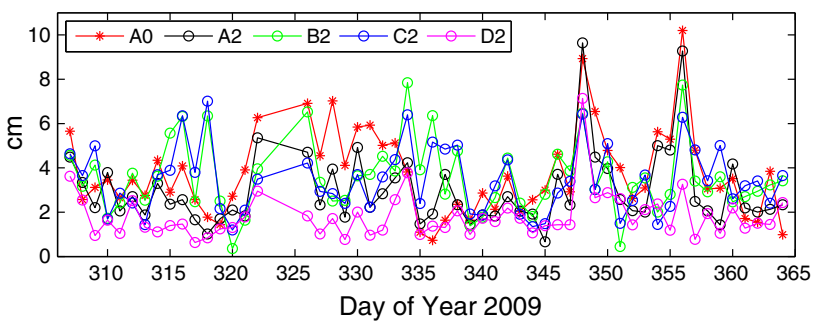

Fig. 15 Orbit differences at midnight for solution types A2-D2 and A0

Table 6 SLR validation for different solution types; mean $(\mathrm{cm}) \pm$ RMS (cm)

\begin{tabular}{llll}
\hline & 0 & 1 & 2 \\
\hline A & $0.35 \pm 2.01$ & $0.31 \pm 2.14$ & $0.31 \pm 1.90$ \\
B & $0.32 \pm 1.99$ & $0.23 \pm 2.01$ & $0.17 \pm 2.02$ \\
C & $0.33 \pm 1.99$ & $0.22 \pm 1.98$ & $0.18 \pm 1.96$ \\
D & $0.34 \pm 1.98$ & $0.28 \pm 1.89$ & $0.22 \pm 1.79$ \\
\hline
\end{tabular}

Looking eventually at the orbit differences for solutions of type 2 in Fig. 15 three issues may be noticed. First, solution A2, which does not use accelerometer data but more realistic constraints than solution A0 has smaller orbit differences than the reference solution A0. Second, solutions B2 and $\mathrm{C} 2$ do not show a common improvement compared to solution A0 and third, solution D2 has clearly the smallest orbit differences of all solution types.

The SLR validation for the different solution types is listed in Table 6, which confirms the results of the orbit difference analysis. The validation for solutions A0-D0 is on a similar level for all four solutions, only a slight improvement may be noticed from A0 toward D0. The solutions B1-D1 have a smaller offset (mean), but except for solution D1 they also are on a similar level as the reference solution A0. Solution A2 has a better SLR validation than solution A0. Solutions $\mathrm{B} 2$ and $\mathrm{C} 2$ have the smallest offest, but the RMS is not yet showing any major improvement. Solution D2, however, is definitely the best solution as viewed by SLR.

From these test series we conclude that, on the one hand, the use of more realistic constraints for the estimated accelerations improves the orbit quality. On the other hand, the simple use of accelerometer data with the same models and parametrization as used for the solutions without accelerometer data does not significantly improve the orbit quality. The combination, however, of realistic constraints and better background models as it is applied for solution D2 is the best choice and improves the orbit quality significantly. The main difference for solution D2 is that it uses a higher truncation (160 instead of 120) of the gravity field model than for solution types $\mathrm{A}-\mathrm{C}$. This result shows also that the unmodeled or not sufficiently well-modeled gravitational forces are still dominant due to the very low orbital altitude. They cannot be absorbed well enough by the estimated 6-min piece-wise constant accelerations.

\section{Summary}

The official GOCE PSO product has been generated very consistently for the entire mission. The reduced-dynamic orbits show for single days only larger values in the overlap statistics. In most cases, larger values occur on days where the satellite was not flying in drag-free mode. The days of the gradiometer calibrations "pop up" in the overlaps of the reduced-dynamic orbits. The satellite shakings cause an additional acceleration, which cannot be fully absorbed by the estimated accelerations in out-of-plane direction using the adopted constraints. This circumstance leads to larger mean offsets in this direction.

The quality of the kinematic orbits slightly decreased towards the end of the mission due to the increased solar activity leading to more tracking problems on the GPS L2 frequency, and thus an increased number of data gaps. The orbit consistency checks in terms of orbit differences between the reduced-dynamic and kinematic orbits revealed this effect. The yearly SLR validation also confirms that the kinematic orbits are more affected by tracking problems and data gaps than the reduced-dynamic orbit. The SLR RMS values are increasing towards the end of the mission, more significantly for the kinematic orbits. The overall SLR validation, however, still indicates an outstanding 1D accuracy of $1.84 \mathrm{~cm}$ for the reduced-dynamic and $2.42 \mathrm{~cm}$ for the kinematic orbits for the entire mission.

Modeling the range corrections of the laser retro-reflector array with a nearest-prism approximation has significantly improved the SLR validation. Introducing the tilt of the reflector array with respect to the satellite body also improved the SLR validation.

A study showed that more realistic constraints derived from the accelerometer data may improve the reduceddynamic orbit results significantly. If one uses the accelerometer data directly in the reduced-dynamic orbit determination procedure and additionally makes use of better background models (mainly using higher truncation than 120 for the grav- 
ity field model) than for the official reduced-dynamic PSO product, the orbit accuracy can be improved even more. Our findings should be considered for a possible reprocessing of the PSO.

Acknowledgments This work was partly performed in the frame of the GOCE High-level Processing Facility (HPF), which is funded by ESA. The support of ESA is gratefully acknowledged. The activities of the CODE analysis center of the IGS provide the basis for our work. CODE is a joint venture of AIUB, Swiss Federal Office of Topography (swisstopo), Wabern, Switzerland, the German Federal Office of Cartography and Geodesy (BKG), Frankfurt a. Main, Germany, and the Institut für Astronomische and Physikalische Geodäsie (IAPG), Technische Universität München, Germany.

\section{References}

Altamimi Z, Collilieux X, Legrand J, Garayt B, Boucher C (2007) ITRF2005: a new release of the international terrestrial reference frame based on time series of station positions and earth orientation parameters. J Geophs Res 112(B9):401-419. doi:10.1029/ 2007JB004949

Andreis D, Canuto E (2005) Drag-free and attitude control for the GOCE satellite. In: 44th IEEE conference on decision and control, 2005 and 2005 European control conference CDC-ECC05, pp 4041-4046. doi:10.1109/CDC.2005.1582794

Basu S, Groves KM (2001) Specification and forecasting of outages on satellite communication and navigation systems. In: Song P, Singer HJ, Siscoe GL (eds) Space weather geophysical monograph series, vol 125, pp 424-430. doi:10.1029/GM125p0423

Baur O, Bock H, Höck E, Jäggi A, Krauss S, Mayer-Gürr T, Reubelt T, Siemes C, Zehentner N (2014) Comparison of GOCE-GPS gravity fields derived by different approaches. J Geod. doi:10.1007/s00190014-0736-6

Bigazzi A, Frommknecht B (2010) Note on GOCE instruments positioning, Issue 3.1. http://earth.esa.int/download/goce/GOCE-LRR-GPSpositioning-Memo_3.1_[XGCE-GSEG-EOPG-TN-09-0007v3.1]

Bock H, Jäggi A, Švehla D, Beutler G, Hugentobler U, Visser P (2007) Precise orbit determination for the GOCE satellite using GPS. Adv Space Res 39(10):1638-1647. doi:10.1016/j.asr.2007.02.053

Bock H, Dach R, Jäggi A, Beutler G (2009) High-rate GPS clock corrections from CODE: support of $1 \mathrm{~Hz}$ applications. J Geod 83(11):10831094. doi:10.1007/s00190-009-0326-1

Bock H, Jäggi A, Meyer U, Dach R, Beutler G (2011) Impact of GPS antenna phase center variations on precise orbits of the GOCE satellite. Adv Space Res 47(11):1885-1893. doi:10.1016/j.asr.2011.01. 017

Bock H, Jäggi A, Meyer U, Visser P, van den IJssel J, van Helleputte T, Heinze M, Hugentobler U, (2011b) GPS-derived orbits for the GOCE satellite. J Geod 85(11):807-818. doi:10.1007/s00190-0110484-9

Bouman J, Fiorot S, Fuchs M, Gruber T, Schrama E, Tscherning C, Veicherts M, Visser P (2011) GOCE gravitational gradients along the orbit. J Geod 85(11):791-805. doi:10.1007/s00190-011-0464-0

Bouman J, Floberghagen R, Rummel R (2013) More than 50 years of progress in satellite gravimetry. EOS Trans Am Geophys Union 94(31):269-274. doi:10.1002/2013EO31

Dach R, Brockmann E, Schaer S, Beutler G, Meindl M, Prange L, Bock H, Jäggi A, Ostini L (2009) GNSS processing at CODE: status report. J Geod 83(3-4):353-365. doi:10.1007/s00190-008-0281-2

Dach R, Beutler G, Bock H, Fridez P, Gäde A, Hugentobler U, Jäggi A, Meindl M, Mervart L, Prange L, Schaer S, Springer T, Urschl C, Walser P (2007) Bernese GPS Software Version 5.0. Astronomical
Institute, University of Bern, Bern, Switzerland. http://www.bernese. unibe.ch/docs/DOCU50, user manual

European GOCE Gravity Consortium (EGG-C) (2010) GOCE Standards, GO-TN-HPF-GS-0111. http://earth.esa.int/pub/ESA_DOC/ GOCE/GOCE_Standards_3.2

Floberghagen R, Fehringer M, Lamarre D, Muzi D, Frommknecht B, Staiger C, Piñeiro J, da Costa A (2011) Mission design, operation and exploitation of the Gravity field and steady-state Ocean Circulation Explorer (GOCE) mission. J Geod 85(11):749-758. doi:10.1007/ s00190-011-0498-3

Förste C, Flechtner F, Schmidt R, Stubenvoll R, Rothacher M, Kusche J, Neumayer H, Biancale R, Lemoine JM, Barthelmes F, Bruinsma S, König R, Meyer U (2008) EIGEN-GL05C-a new global combined high-resolution GRACE-based gravity field model of the GFZGRGS cooperation. Geophys Res Abstr 10, EGU2008-A-03426

Frommknecht B, Lamarre D, Meloni M, Bigazzi A, Floberghagen R (2011) GOCE level1b data processing. J Geod 85(11):759-775. doi:10.1007/s00190-011-0497-4

van Helleputte T, Doornbos E, Visser P (2009) CHAMP and GRACE accelerometer calibration by GPS-based orbit determination. Adv Space Res 43(12):1890-1896. doi:10.1016/j.asr.2009.02.017

Jäggi A (2007) Pseudo-stochastic orbit modeling of low earth satellites using the global positioning system. Geodätisch-geophysikalische Arbeiten in der Schweiz, Band 73, Schweizerische Geodätische Kommission, Institut für Geodäsie und Photogrammetrie, Eidg. Technische Hochschule Zürich, Zürich

Jäggi A, Hugentobler U, Beutler G (2006) Pseudo-stochastic orbit modeling techniques for low-Earth orbiters. J Geod 80(1):47-60. doi:10. 1007/s00190-006-0029-9

Jäggi A, Dach R, Montenbruck O, Hugentobler U, Bock H, Beutler G (2009) Phase center modeling for LEO GPS receiver antennas and its impact on precise orbit determination. J Geod 83(12):1145-1162. doi:10.1007/s00190-009-0333-2

Jäggi A, Bock H, Floberghagen R (2011) GOCE orbit predictions for SLR tracking. GPS Solut 15(2):129-137. doi:10.1007/s10291-0100176-6

Jäggi A, Montenbruck O, Moon Y, Wermuth M, König R, Michalak G, Bock H, Bodenmann D (2012) Inter-agency comparison of TanDEM-X baseline solutions. Adv Space Res 50(2):260-271. doi:10.1016/j.asr.2012.03.027

Jäggi A, Bock H, Meyer U, Beutler G, van den IJssel J (2014) GOCE Assessment of GPS-only gravity field estimation. J Geod, in review

Jäggi A, Hugentobler U, Bock H, Beutler G (2007) Precise orbit determination for GRACE using undifferenced or doubly differenced GPS data. Adv Space Res 39(10):1612-1619. doi:10.1016/j.asr.2007.03. 012

Kang Z, Tapley B, Bettadpur S, Ries J, Nagel P (2006) Precise orbit determination for GRACE using accelerometer data. Adv Space Res 38(9):2131-2136. doi:10.1016/j.asr.2006.02.021

Koop R, Gruber T, Rummel R (2006) The status of the GOCE high-level processing facility. In: Proceedings of the 3rd GOCE user workshop, 6-8 November 2006, Frascati, Italy, ESA SP-627, pp 199-205

Loiselet M, Stricker N, Menard Y, Luntama JP (2000) GRAS MetOps GPS-based atmospheric sounder. ESA Bull 102:3844

Lyard F, Lefevre F, Letellier T, Francis O (2006) Modelling the global ocean tides: insights from FES2004. Ocean Dynam 56:394-415. doi:10.1007/s10236-006-0086-x

Mayer-Gürr T, Rieser D, Hoeck E, Brockmann JM, Schuh WD, Krasbutter I, Kusche J, Maier A, Krauss S, Hausleitner W, Baur O, Jäggi A, Meyer U, Prange L, Pail R, Fecher T, Gruber T (2012) The new combined satellite only model GOCO03s. In: International symposium on gravity, geoid and height systems GGHS (2012) Venice. Italy, Presentation

McCarthy DD, Petit G (2004) IERS Conventions 2003. IERS Technical note no.32. Bundesamt für Kartographie und Geodäsie, Frankfurt am Main, Germany 
Meindl M, Beutler G, Thaller D, Dach R, Jäggi A (2013) Geocenter coordinates estimated from GNSS data as viewed by perturbation theory. Adv Space Res 51(7):1047-1064. doi:10.1016/j.asr.2012.10. 026

Montenbruck O, Andres Y, Bock H, van Helleputte T, van den IJssel J, Loiselet M, Marquardt C, Silvestrin P, Visser P, Yoon Y, (2008) Tracking and orbit determination performance of the GRAS instrument on MetOp-A. GPS Solut 12(4):289-299. doi:10.1007/s10291008-0091-2

Montenbruck O, Neubert R (2011) Range correction for the CryoSat and GOCE laser retro-reflector arrays. Technical Note DLR/GSOC $11-01$

Pearlman M, Degnan J, Bosworth J (2002) The international laser ranging service. Adv Space Res 30(2):135-143. doi:10.1016/S02731177(02)00277-6

Reigber C, Lühr H, Schwintzer P (2002) CHAMP mission status. Adv Space Res 30(2):129-134. doi:10.1016/S0273-1177(02)00276-4

Rummel R, Yi W, Stummer C (2011) GOCE gravitational gradiometry. J Geod 85(11):777-790. doi:10.1007/s00190-011-0500-0

Savcenko R, Bosch W (2008) EOT08a-empirical ocean tide model from multi-mission satellite altimetry. DGFI Report 81, Deutsches Geodätisches Forschungsinstitut, Munich, Germany

Schmid R, Steigenberger P, Gendt G, Ge M, Rothacher M (2007) Generation of a consistent absolute phase center correction model for GPS receiver and satellite antennas. J Geod 81(12):781-798. doi:10. 1007/s00190-007-0148-y
SP-1272 E (2003) CryoSat science report. ESA Publications Division Standish EM (1998) JPL Planetary and Lunar Ephemerides, DE405/LE405. JPL IOM 312.F-98-048

Švehla D, Rothacher M (2005) Kinematic precise orbit determination for gravity field determination. In: Sansò $F$ (ed) The proceedings of the international association of geodesy, A Window on the Future of Geodesy, IUGG General Assembly 2003, vol 128, June 30-July 11, 2003, Springer, Sapporo, Japan. pp 181-188. doi10.1007/3-54027432-4_32

Tapley B, Bettadpur S, Ries J, Watkins M (2004) GRACE measurements of mass variability in the Earth system. Science 305(5683):503-505

van den IJssel J, Visser P, Doornbos E, Meyer U, Bock H, Jäggi A (2011) GOCE SSTI L2 tracking losses and their impact on POD performance. In: Proceedings of 4th international GOCE user workshop, 31 March-1 April, 2011, TU München, Munich, Germany, ESA, ESA communications

van Helleputte T (2011) The integration of spaceborne accelerometry in the precise orbit determination of low-flying satellites. $\mathrm{PhD}$ thesis, Delft University of Technology

Visser P, van den IJssel J, van Helleputte T, Bock H, Jäggi A, Beutler G, Švehla D, Hugentobler U, Heinze M (2009) Orbit determination for the GOCE satellite. Adv Space Res 43(5):760-768. doi:10.1016/ j.asr.2008.09.016 